\title{
Cre Recombinase Driver Mice Reveal Lineage- Dependent and -Independent Expression of Brs3 in the Mouse Brain
}

\author{
Allison S. Mogul, ${ }^{1, *}$ Colleen K. Hadley, ${ }^{1, *}$ Haley S. Province, ${ }^{1, *}$ Jordan Pauli, ${ }^{2}$ Oksana Gavrilova, ${ }^{3}$ \\ Cuiying Xiao, ${ }^{1}$ Richard D. Palmiter, ${ }^{2}$ Ramón A. Piñol, ${ }^{1}$ and ${ }^{\circ}$ Marc L. Reitman ${ }^{1}$
}

https://doi.org/10.1523/ENEURO.0252-21.2021

${ }^{1}$ Diabetes, Endocrinology, and Obesity Branch, National Institute of Diabetes and Digestive and Kidney Diseases, National Institutes of Health, Bethesda, Maryland 20892, ${ }^{2}$ Department of Biochemistry, Genome Sciences, and Howard Hughes Medical Institute, University of Washington, Seattle, Washington 98195, and ${ }^{3}$ Mouse Metabolism Core, National Institute of Diabetes and Digestive and Kidney Diseases, National Institutes of Health, Bethesda, Maryland 20892

\begin{abstract}
Bombesin receptor subtype-3 (BRS3) is an orphan receptor that regulates energy homeostasis. We compared Brs3 driver mice with constitutive or inducible Cre recombinase activity. The constitutive BRS3-Cre mice show a reporter signal (Cre-dependent tdTomato) in the adult brain because of lineage tracing in the dentate gyrus, striatal patches, and indusium griseum, in addition to sites previously identified in the inducible BRS3-Cre mice (including hypothalamic and amygdala subregions, and parabrachial nucleus). We detected Brs3 reporter expression in the dentate gyrus at day 23 but not at postnatal day 1 or 5 months of age. Hypothalamic sites expressed reporter at all three time points, and striatal patches expressed Brs 3 reporter at 1 day but not 5 months. Parabrachial nucleus Brs3 neurons project to the preoptic area, hypothalamus, amygdala, and thalamus. Both Cre recombinase insertions reduced Brs3 mRNA levels and BRS3 function, causing obesity phenotypes of different severity. These results demonstrate that driver mice should be characterized phenotypically and illustrate the need for knock-in strategies with less effect on the endogenous gene.
\end{abstract}

Key words: bombesin receptor subtype-3; BRS3; Cre recombinase driver mice; dentate gyrus; hypothalamus; lineage tracing; parabrachial nucleus

\section{Significance Statement}

Bombesin receptor subtype-3 (BRS3) expression is a marker for selected neurons that regulate body temperature and energy metabolism, among other functions. BRS3-Cre recombinase driver mice allow investigation of these neurons, demonstrating discrete populations with stable (including hypothalamic and amygdala subregions, parabrachial nucleus) and developmentally transient expression (dentate gyrus, striatal patches). These mice also illustrate the need for knock-in strategies having less effect on proper expression of the endogenous gene.

\section{Introduction}

Bombesin receptor subtype-3 (BRS3, Bombesin-like receptor 3, BB3) is a G-protein-coupled receptor critical for the maintenance of energy balance (Jensen et al., 2008; González et al., 2015; Xiao and Reitman, 2016). BRS3 is considered an orphan receptor as its endogenous ligand is not known; specifically, it does not bind the natural ligands (gastrin-releasing peptide and neuromedin B) for the most closely related receptors (Mantey et al., 1997); nor does it bind bombesin, which is

Author contributions: R.D.P. and M.L.R. designed research; A.S.M., C.K.H., H.S.P., J.P., O.G., C.X., and R.D.P. performed research; A.S.M., C.K.H., H.S.P., J.P., O.G., C.X., R.D.P., R.A.P., and M.L.R. analyzed data; M.L.R. wrote the paper. 
the frog ortholog of neuromedin B (Hirooka et al., 2021). Mice lacking BRS3 are hyperphagic, have a reduced resting metabolic rate and body temperature, and consequently become obese (Ohki-Hamazaki et al., 1997b). Brs3 knock-out (KO) mice are also reported to exhibit reduced social responses, a heightened preference for sweetness, and increased aversion to bitterness (Yamada et al., 1999, 2000). Although Brs3 is also expressed outside the CNS (Jensen et al., 2008), the metabolic phenotypes of Brs3 KO mice are predominantly mediated by glutamatergic Brs3 neurons, with contributions from neurons expressing MC4R and SIM1 demonstrating the necessity of brain BRS3 (Xiao et al., 2017, 2020). Consistent with the phenotypes of BRS3-null mice, administration of a BRS3 agonist reduces food intake and body weight and increases brown adipose tissue (BAT)-induced thermogenesis, heart rate, and blood pressure, while BRS3 antagonists increase food intake and body weight (Guan et al., 2010, 2011; Nio et al., 2017; Maruyama et al., 2018). Single doses of a BRS3 agonist increased blood pressure in humans (Reitman et al., 2012), likely via increased sympathetic tone (Lateef et al., 2016), reducing interest in central agonism as a human therapeutic for obesity and stimulating interest in studying BRS3 agonists that do not enter the brain (Kiyotsuka et al., 2016).

While pharmacologic and genetic manipulations of BRS3 have revealed the functions of the receptor, BRS3 can also be used as a marker for studying the neural circuitry regulating energy homeostasis. BRS 3 is found in discrete brain regions in the mouse (Ohki-Hamazaki et al., 1997a; Yamada et al., 1999; Guan et al., 2010; Zhang et al., 2013; Piñol et al., 2018; see also Allen Mouse Brain Atlas) and other species (Liu et al., 2002; Sano et al., 2004; Zhang et al., 2013; Maruyama et al., 2018). The contributions of hypothalamic Brs3 neurons to energy homeostasis are heterogeneous. Brs3 neurons in the paraventricular hypothalamus $(\mathrm{PVH})$ regulate food intake, but not body temperature or BAT thermogenesis. In contrast, Brs3 neurons in the preoptic area (POA) of the hypothalamus and dorsomedial hypothalamus $(\mathrm{DMH})$ regulate body temperature, energy expenditure, heart rate, and blood pressure, but not appetite (Piñol et al., 2018, 2021). POA Brs3 neurons have also been implicated in parental behaviors (Moffitt et al., 2018; Yoshihara et al., 2021).

We previously generated a tamoxifen-dependent BRS3Cre driver mouse line (hereafter called BRS3-CreER) and used it to elucidate the anatomy, connectivity, and physiology

This research was funded by the Intramural Research Program of the National Institutes of Health, National Institute of Diabetes and Digestive and Kidney Diseases (Grants ZIA-DK-075057, ZIA-DK-075062, and ZIA-DK075063).

${ }^{*}$ A.S.M. C.K.H., and H.S.P. contributed equally to this work.

Acknowledgements: We thank Naili Liu for assistance with telemetry studies.

Correspondence should be addressed to Marc L. Reitman at marc. reitman@nih.gov.

https://doi.org/10.1523/ENEURO.0252-21.2021

Copyright ( $\odot 2021$ Mogul et al.

This is an open-access article distributed under the terms of the Creative Commons Attribution 4.0 International license, which permits unrestricted use, distribution and reproduction in any medium provided that the original work is properly attributed. of neurons expressing Brs3 (Piñol et al., 2018). Here we characterize a new, constitutive BRS3-Cre allele (hereafter called BRS3-IRES (internal ribosomal entry site)-Cre) and show that the BRS3-IRES-Cre driver can be used for lineage tracing. In both BRS3-Cre lines, the Cre insertion affects Brs3 expression and function in whole-body physiology. These results provide guidance and have general implications for developing driver mice.

\section{Materials and Methods}

\section{Mice}

Procedures were approved by the National Institute of Diabetes and Digestive and Kidney Diseases and the University of Washington Animal Care and Use Committees (protocols K016-DEOB-20 and 2183-02, respectively). The following mice were used: C57BL/6J (catalog \#000664, The Jackson Laboratory); Ai14, with Credependent expression of tdTomato (catalog \#007914, The Jackson Laboratory; Madisen et al., 2010); BRS3-CreER, with tamoxifen-dependent Cre activity (catalog \#032614, The Jackson Laboratory; allele is Brs ${ }^{\text {tm } 3.1 \text { (cre/ERT2)Rei; Piñol }}$ et al., 2018); and BRS3-IRES-Cre, with constitutive Cre activity (described below; catalog \#030540, The Jackson

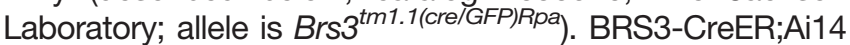
mice showed no evidence of tamoxifen-independent germline recombinase activity in $>100$ progeny as assessed by the lack of generalized tdTomato expression. Mice were studied on a C57BL/6J background. Male mice were used since $\mathrm{Brs} 3$ is on the $\mathrm{X}$ chromosome and undergoes $\mathrm{X}$-inactivation (Piñol et al., 2018). Mice were housed on a $12 \mathrm{~h}$ dark/ light cycle (lights on at 6:00 A.M.), at $\sim 22^{\circ} \mathrm{C}$, with Teklad bedding (catalog \#7090, Envigo) and ad libitum access to water and chow $(15 \% \mathrm{kcal}$ fat; energy density, $3.1 \mathrm{kcal} / \mathrm{g}$; catalog \#7022 NIH-07 diet; Envigo) or high fat diet (HFD; $60 \%$ kcal fat; 5.24 metabolizable kcal/g; catalog \#D12492, Research Diets) in a clean conventional vivarium. BRS3CreER mice were genotyped as described previously (Piñol et al., 2018). Both BRS3-CreER and BRS3-IRES-Cre mice can be propagated in the homozygous state (i.e., hemizygous males $x$ homozygous females) without apparent effects on fertility.

\section{Generation of BRS3-IRES-Cre mice}

A cassette encoding IRES-mnCre:GFP was inserted 3' of the termination codon in the last coding exon of the Brs3 gene. The $5^{\prime}$ arm ( $~ 6 \mathrm{~kb}$ with Spel and Sall sites at $5^{\prime}$ and $3^{\prime}$ ends, respectively) and $3^{\prime}$ arm $(\sim 5.7 \mathrm{~kb}$ with Xhol and Notl sites at $5^{\prime}$ and $3^{\prime}$ ends, respectively) of the Brs3 gene were subcloned from a C57BL/6 BAC clone and cloned into polylinkers of a targeting construct that contained IRES-mnCre:GFP, a frt-flanked Sv40Neo gene for positive selection, and HSV thymidine kinase and Pgkdiphtheria toxin $A$ chain genes for negative selection. The IRES-mnCre:GFP cassette has an IRES, a Myc-tag, and nuclear localization signals at the $\mathrm{N}$ terminus of Cre recombinase, which is fused to green fluorescent protein followed by an SV40 polyadenylation. The construct was electroporated into G4 ES cells (C57BL/6 $\times 129$ Sv hybrid), and correct targeting was determined by Southern 
blot of DNA digested with Kpnl using a ${ }^{32} \mathrm{P}$-labeled probe upstream of the $5^{\prime}$ arm of the targeting construct. Of the 75 clones analyzed, 44 were correctly targeted. One clone that was injected into blastocysts resulted in good chimeras that transmitted the targeted allele through the germline. Progeny were bred with Gt(Rosa)26Sor-FLP recombinase mice to remove the frt-flanked SV-Neo gene. Mice were then continuously backcrossed to C57BL/6 mice. BRS3-IRES-Cre;Ai14 mice showed no evidence of germline recombinase activity in 12 progeny as assessed by lack of generalized tdTomato expression. Routine genotyping is performed with the following three primers: X717 5' CTG CCT CAA GGC AGA GCA GC (Brs3 forward); X718 5' CCT CTT CTT CTC TAC TTG GTG GGC (Brs3 reverse); and X719 5' GCT TCG GCC AGT AAC GTT AGG (IRES reverse). The wild-type allele gives a band of $\sim 350 \mathrm{bp}$, while the targeted allele gives a band of $270 \mathrm{bp}$ after 34 cycles with $20 \mathrm{~s}$ annealing at $60^{\circ} \mathrm{C}$.

\section{Stereotactic virus injection and imaging}

Mice at 3-5 months of age were anesthetized with ketamine/xylazine $(80 / 10 \mathrm{mg} / \mathrm{kg}$, i.p.), placed in a stereotaxic instrument (Digital Just for Mouse Stereotaxic Instrument, Stoelting), and ophthalmic ointment (Puralube, Dechra) was applied. Injections were made with pulled-glass pipettes (tip diameter, 20-40 $\mu \mathrm{m}$; inner diameter, $0.275 \mathrm{~mm}$; outer diameter, $1 \mathrm{~mm}$; Wilmad Lab Glass) at a visually controlled rate of $50 \mathrm{nl} / \mathrm{min}$ using an air pressure system regulator (model S48 stimulator, Grass Technologies). Virus pAAV1-CAG-FLEX-EGFP (a gift from Hongkui Zeng Allen Institute for Brain Science, Seattle WA; viral prep \#51502-AAV1, Addgene; RRID:Addgene_51502; Oh et al., 2014) was injected unilaterally into the striatum (200 $\mathrm{nl}$; AP, $0.74 \mathrm{~mm}$; ML, 2.00; DV, -3.5), dentate gyrus (DG; $50 \mathrm{nl}$; AP, $-2.00 \mathrm{~mm}$; ML, $1.5 \mathrm{~mm}$; DV, $-2.0 \mathrm{~mm}$ ), and $\mathrm{DMH}$ (50 nl; AP, -1.85; ML, 0.3; DV, $-5.05 \mathrm{~mm}$ ), with the pipette being kept in place for $5 \mathrm{~min}$ after each injection. Postsurgery, mice received subcutaneous sterile saline injections and analgesic (buprenorphine, $0.1 \mathrm{mg} / \mathrm{kg}$, i.p.). BRS3-CreER mice were given tamoxifen $(110 \mathrm{mg} / \mathrm{kg}$ in corn oil, i.p.) for 5 consecutive days starting a week after surgery. Approximately 1 month after surgery, mice were perfused, and brains were fixed in $10 \%$ formalin for $1 \mathrm{~d}$, transferred to $30 \%$ sucrose overnight, sliced $(50 \mu \mathrm{m})$ on a freezing microtome (Leica), collected in three series, and one series was mounted with medium containing DAPI (Prolong Gold, Thermo Fisher Scientific). Immunohistochemistry for tdTomato on postnatal day 1 (P1) and P23 BRS3-IRES-Cre;Ai14 brain sections was performed as described previously (Piñol et al., 2018) with the exception of using 5\% normal horse serum and a $2 \mathrm{~h}$ blocking incubation before overnight incubation with primary antibody. Slides were imaged with a VS120 slide scanner and OlyVIA software (Olympus) and a Axio Observer Z1 microscope (Zeiss) with a $10 \times$ objective, Zeiss 700 confocal hardware, and Zen software (Zeiss). Brain regions were assigned according to the study by Franklin and Paxinos (2007).

\section{Parabrachial nucleus neuron projection tracing}

Male BRS3-IRES-Cre mice were anesthetized with isoflurane and placed on a robotic stereotaxic frame (Neurostar). AAV-1EF1a-DIO-YFP and AAV1-EF1a-DIOsynaptophysin:mCherry were injected bilaterally into the parabrachial nucleus (PBN; $200 \mathrm{nl}$; AP, $-4.8 \mathrm{~mm}$; ML, $\pm 1.4 \mathrm{~mm}$; DV,$-3.5 \mathrm{~mm}$ ) at a rate of $0.1 \mu \mathrm{l} / \mathrm{min}$ for $2 \mathrm{~min}$ with the needle left in place for the following $5 \mathrm{~min}$. After surgery, mice were allowed to recover for $\sim 3$ weeks. Following recovery, mice were anesthetized with phenytoin/pentobarbital and perfused with PBS, $\mathrm{pH} 7.4$, followed by $4 \%$ paraformaldehyde (PFA) in $0.1 \mathrm{M}$ phosphate buffer, $\mathrm{pH} 7.4$. Brains were removed and placed in $4 \%$ PFA to postfix for $24 \mathrm{~h}$ and were subsequently placed in $30 \%$ sucrose for several days before being embedded in OCT compound and stored at $-80^{\circ} \mathrm{C}$. Coronal sections $(35 \mu \mathrm{m})$ were cut on a cryostat (Leica Microsystems) and collected in cryoprotectant for long-term storage at $-20^{\circ}$ C. To enhance the signal, sections were washed three times in PBS for $5 \mathrm{~min}$ and incubated in a blocking solution [3\% normal donkey serum in PBS with Tween 20 (PBST)] for $1 \mathrm{~h}$ at room temperature. Sections were incubated overnight at $4^{\circ} \mathrm{C}$ in PBST with the primary antibodies chicken-antiGFP (1:10,000; catalog \#ab13970, Abcam) and rabbit-antiDsRed (1:1000; catalog \#632496, Takara Bio). The following day, sections were washed three times in PBS and then incubated for $1 \mathrm{~h}$ in PBS with the secondary antibodies Alexa Fluor 488 donkey anti-chicken and Alexa Fluor 594 donkey anti-rabbit (1:500; Jackson ImmunoResearch). Sections were then washed three times in PBS, mounted onto glass slides, and coverslipped with Fluoromount-G with DAPI (Southern Biotech). Images were acquired using a Keyence BZ-X700 microscope and an Olympus confocal microscope (model FV-1200, Olympus).

\section{RNA analysis}

Male mice, 5-6 months old, were killed with $\mathrm{CO}_{2}$. Brains were removed and put on an ice-chilled brain matrix, and $1 \mathrm{~mm}$ coronal brain slices were cut with a razor blade and transferred to a microscope slide. The dorsal striatum (0$1 \mathrm{~mm}$ from bregma), and hippocampus and hypothalamus (both -1 to $-2 \mathrm{~mm}$ from bregma) were microdissected with a scalpel and immediately frozen on dry ice and stored at $-80^{\circ} \mathrm{C}$ until processed for RNA. The hypothalamus included $\mathrm{DMH}$, ventromedial hypothalamus $(\mathrm{VMH})$, Arc, lateral hypothalamus (LH), and PVH. RNA from microdissected tissue was isolated as reported (Xiao et al., 2015) and quantitated using QuantStudio 7 Flex Real-Time PCR System (Applied Biosystems), normalized to TATA-box binding protein (Tbp). The primers are as follows: Brs3, x575 (5'-GCACCCTGAACATAC CGACT) and x576 (5'-ACAGGAGATGATTCGGCAAC); Cre, x760 (5'-ATGCTTCTGTCCGTTTGCCG) and x761 (5'-GACCGACGATGAAGCATGTT); tdTomato, x762 (5'CCCGCCGACATCCCCGACTA) and x763 (5'-GGGTCAC GGTCACCACGCC); Mc4r, x581 (5'-ATCTGTAGCTCCTT GCTCGC) and x582 (5'-TGCAAGCTGCCCAGATACAA); and Tbp, x764 (5'-TTTGGCCAGATACATTCCG) and x765 (5'-AACAATTTACAAGCTGCGTTT). 

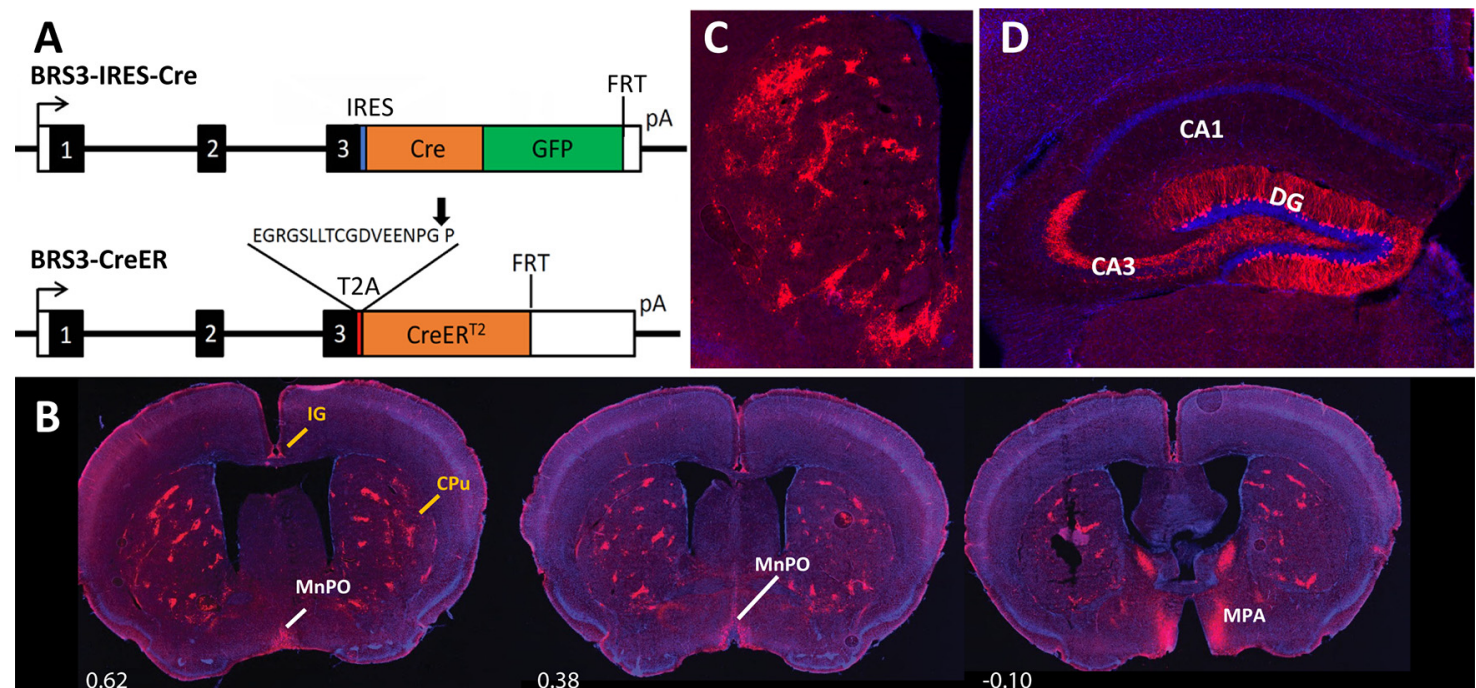

0.62
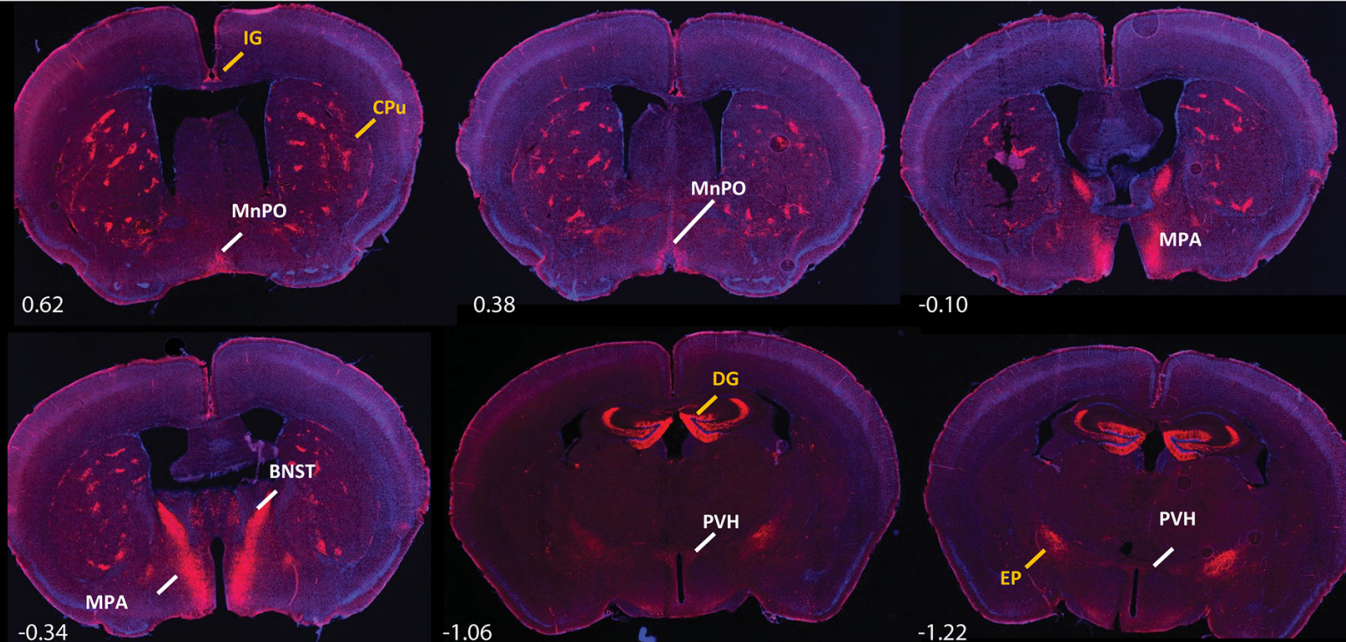

0.38

$-0.10$

$-1.06$
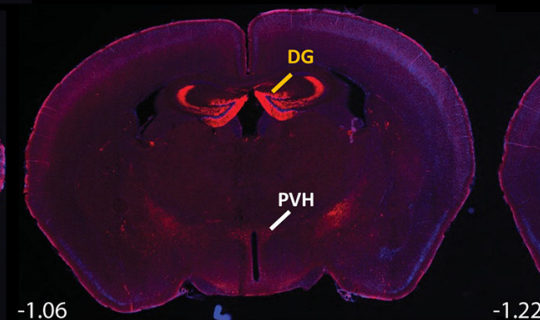

$-1.22$
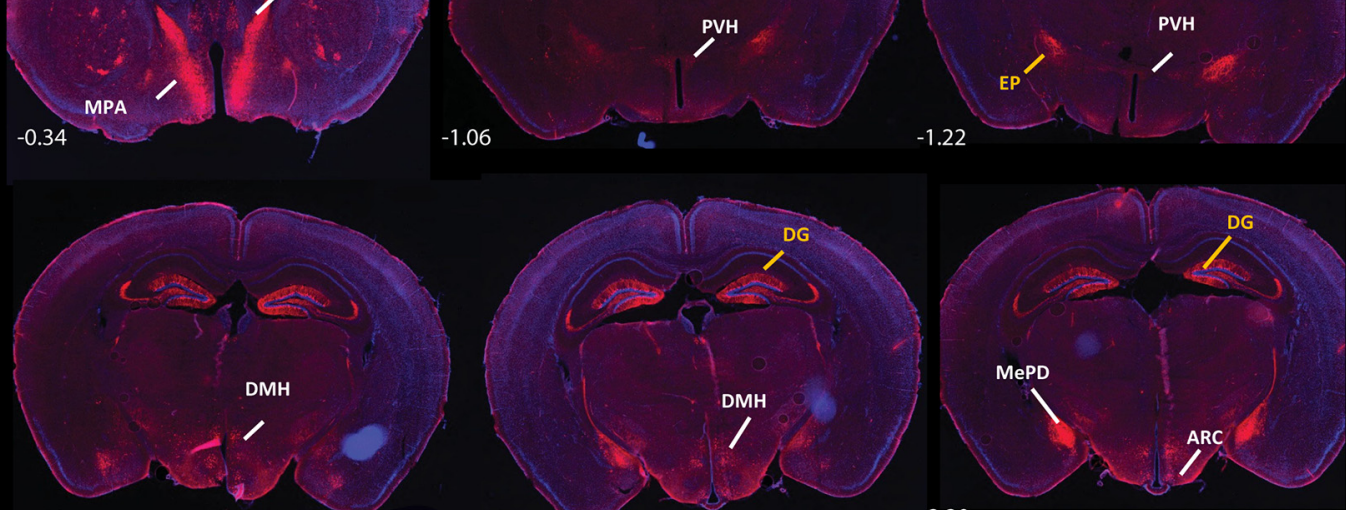

$-1.82$
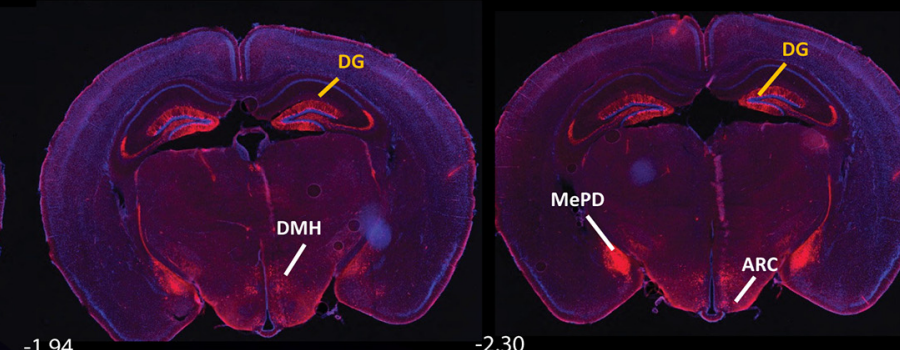

$-2.30$

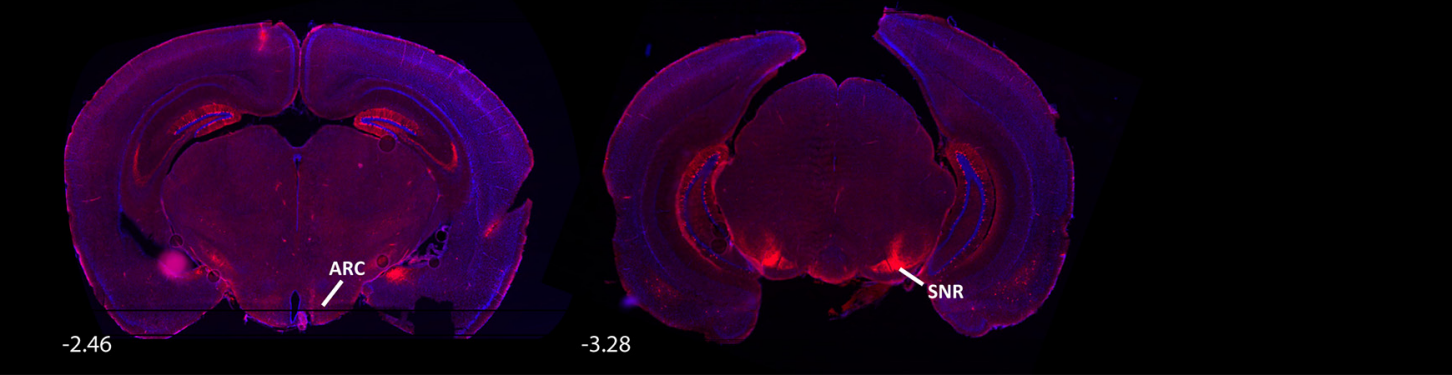

Figure 1. Reporter expression pattern in BRS3-IRES-Cre mice. A, Schematic of the BRS3-IRES-Cre (top) and BRS3-CreER (bottom) alleles. The three exons are numbered with BRS3 coding sequences in black, untranslated regions in white, IRES in blue, T2A in red (with cleavage point indicated by an arrow), Cre in orange, and GFP in green. B, Reporter expression in coronal sections from 5month-old male BRS3-IRES-Cre;Ai14 mice at the indicated level from bregma. Labels in yellow denote reporter detected in BRS3IRES-Cre but not BRS3-CreER mice and white labels are sites expressing reporter in both lines. Arc, Arcuate hypothalamic nucleus; $\mathrm{DMH}$, dorsomedial hypothalamic nucleus. The EP and SNR fluorescence is from fibers; the rest are from cell bodies. $\boldsymbol{C}, \boldsymbol{D}$, Striatum (C) and hippocampus $(\boldsymbol{D})$ at higher magnification. CA1, field CA1; CA3, field CA3.

\section{Mouse phenotyping}

BRS3-IRES-Cre and littermate control mice were singly housed at 9 weeks of age and placed on a HFD at 11 weeks of age for metabolic studies, as described previously (Xiao et al., 2017). Another cohort of BRS3-IRES-
Cre and littermate control mice was singly housed and maintained on chow diet and was used for measuring core body temperature $(\mathrm{Tb})$ by telemetry as described previously (Xiao et al., 2017). Effects of MK-5046 on food intake and Tb were evaluated as reported previously (Xiao 
A BRS3-CreER;Ai14

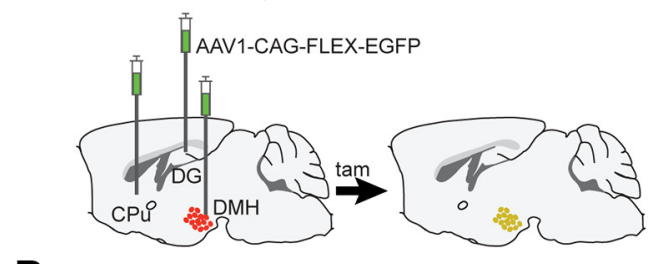

B
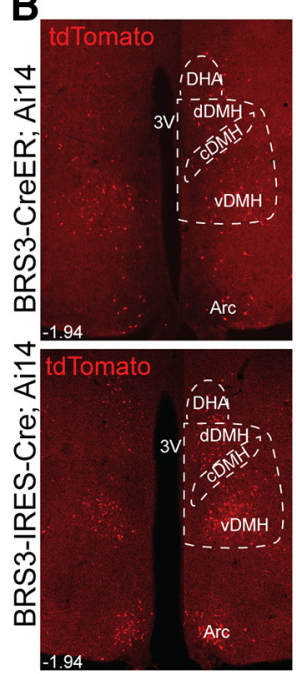

D

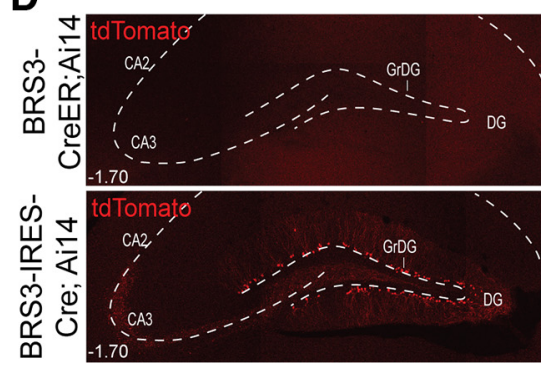

BRS3-IRES-Cre;Ai14

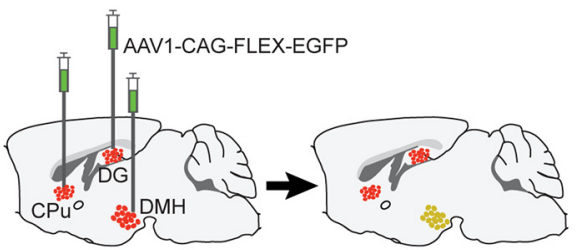

$c$
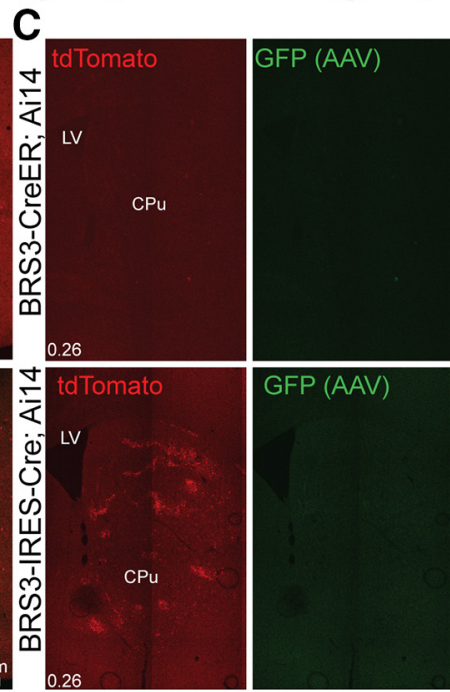

Merged
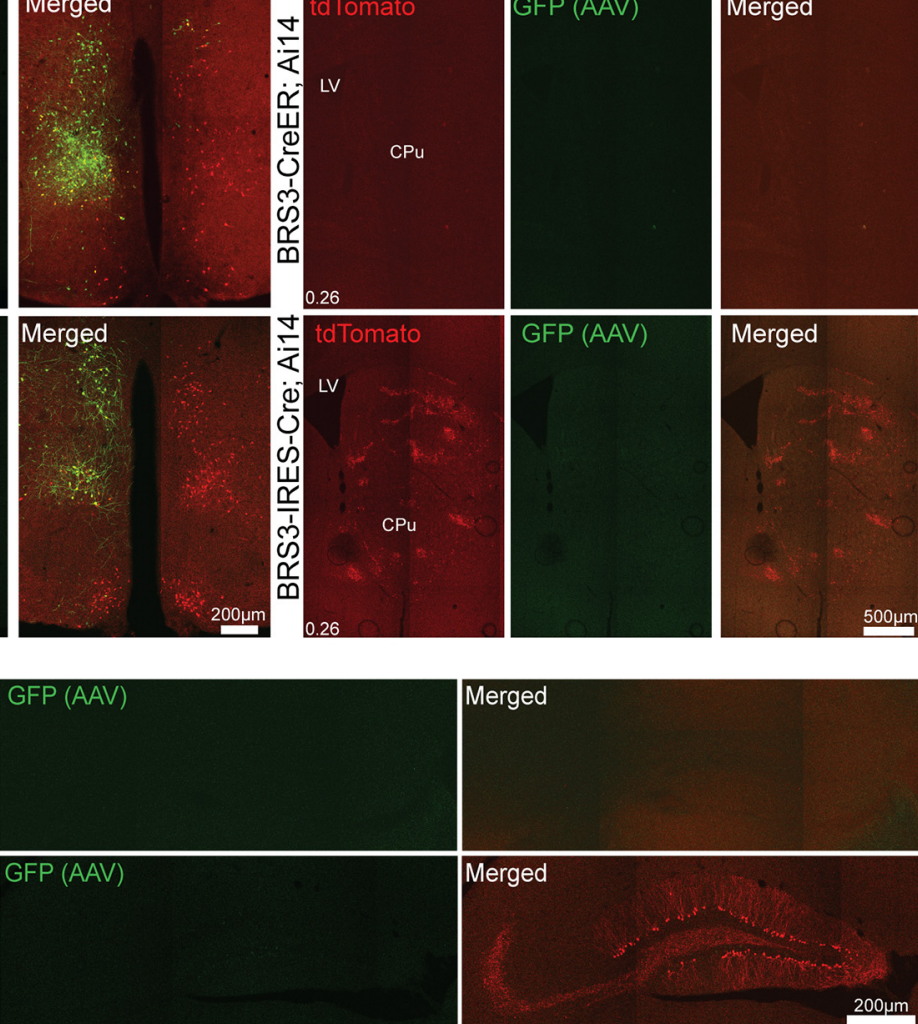

Figure 2. Current compared with lineage Brs3 reporter expression. A, BRS3-CreER;Ai14 and BRS3-IRES-Cre;Ai14 (3- to 5-monthold) mice were injected unilaterally with AAV1-CAG-FLEX-EGFP carrying Cre-dependent GFP. The presence of tdTomato indicates either prior or current Cre activity, while GFP indicates Cre activity at the time of virus injection/tamoxifen treatment, 2 weeks before being killed. $\boldsymbol{B}-\boldsymbol{D}, \mathrm{DMH}(\boldsymbol{B})$, striatum $(\boldsymbol{C})$, and hippocampus $(\boldsymbol{D})$. Bregma levels are indicated.

et al., 2020), with the exception that for testing the effect of MK-5046 on food intake mice were fasted for $5 \mathrm{~h}$ and dosed 30 min before lights off, and chow intake was measured for the first $2 \mathrm{~h}$ after the entry of dark phase.

\section{Single-cell RNA analysis}

Single-cell or single-nucleus count matrices were downloaded from GEO and analyzed with R (version 4.0.2). The total number of cells and number of cells with at least one detectable Brs3 transcript were evaluated for each dataset. True single-cell RNA (scRNA) Brs3 positivity rates were estimated from both raw and normalized data by calculating the Poisson mean that would produce the observed ratio of (cells with one Brs3 transcript)/(cells with greater than one Brs3 transcript) and of (cells with one Brs3 transcript)/(cells with two Brs3 transcripts). Brs3 expression in the dentate gyrus was visualized using dataset $C$ [from the Linarsson Lab (http://linnarssonlab.org/dentate/); Hochgerner et al., 2018].
In the Arc-ME dataset GSE93374 (Campbell et al., 2017), of the 13,079 neurons, 552 expressed at least one Brs3 transcript, and these neurons were clustered using Seurat (version 3.2.0; Butler et al., 2018; Stuart et al., 2019). Raw counts were normalized, scaled, and the 2000 most variable genes were used as input for principal component analysis. A resolution of 0.6 and 20 principal components were used for the clustering analysis, which was visualized with $\mathrm{t}$-SNE (t-distributed stochastic neighbor embedding). The resolution (0.4-1.0) and principal components (10-30) were varied to confirm the robustness of the clustering. Neither condition (e.g., diet, sex, fasted state) nor batch were major drivers of the clustering. Differentially expressed genes (DEGs) and cluster marker genes were identified using the Wilcoxon rank-sum test. The top five DEGs for each cluster (based on average $\log _{2}$-fold change) were visualized by heatmap. Cluster names were assigned with one or more significantly enriched marker genes (average $\log _{2}$-fold change, $>1.4$; 

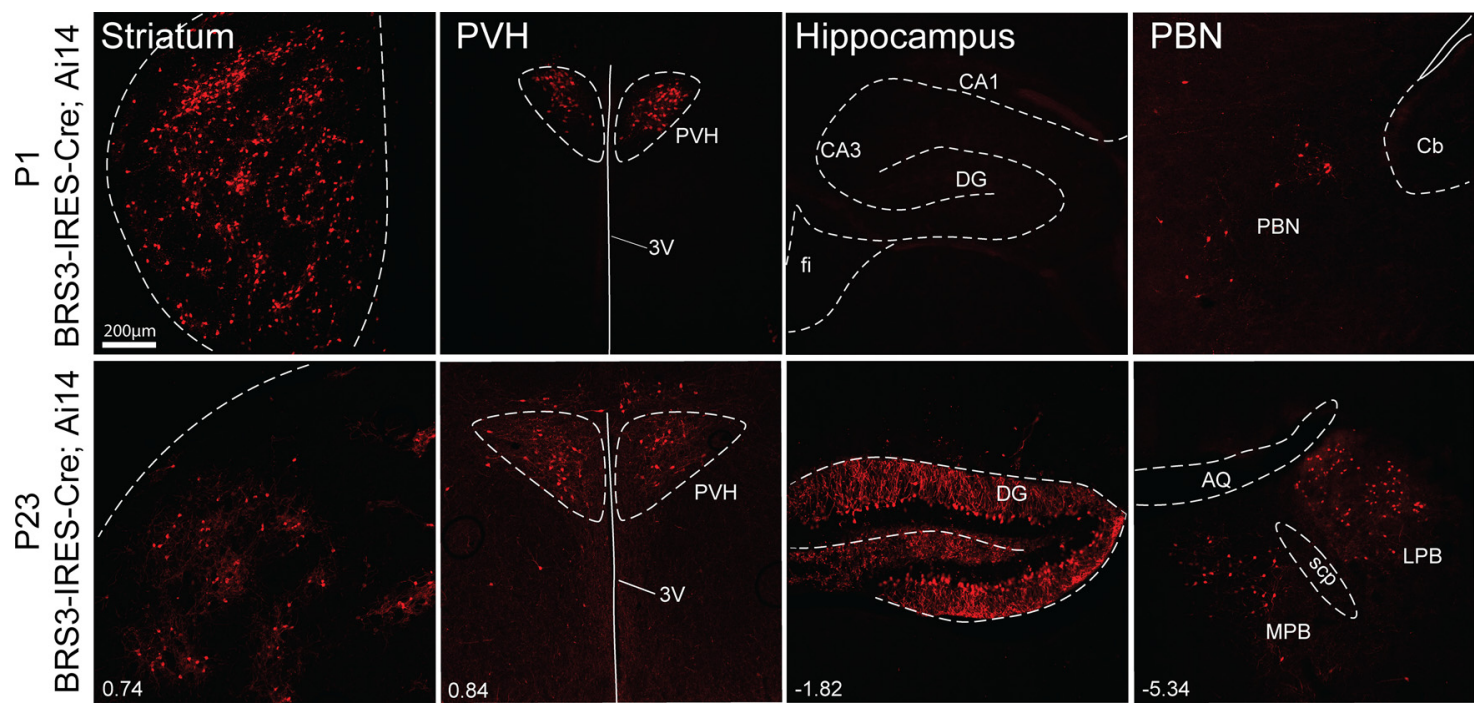

Figure 3. BRS3-IRES-Cre-driven reporter expression in young mice. tdTomato reporter expression in BRS3-IRES-Cre;Ai14 mice at P1 (top row) and P23 (bottom row). Scale bar, $200 \mu \mathrm{m}$. Bregma levels are indicated. 3V, Third ventricle; fi, fimbria; Cb, cerebellum; $A Q$, cerebral aqueduct; scp, superior cerebellar peduncles; LPB, lateral parabrachial nucleus; MPB, medial parabrachial nucleus.

false discovery rate-adjusted $p$ value, $<7.5 \mathrm{E}-41$ ), with the exception of one "unassigned" cluster in which all DEGs had an average $\log _{2}$-fold change of $\leq 0.71$.

\section{Results}

\section{Reporter expression in BRS3-IRES-Cre;Ai14 mice}

There are currently two BRS3-Cre driver mouse lines available, one constructed by inserting a Cre recombinase sequence just after the stop codon of the Brs3 locus (BRS3-IRES-Cre) and the other with the insertion of T2A-CreERT2 at the stop codon (BRS3-CreER; Fig. 1A). In BRS3-IRES-Cre mice, the Cre recombinase is constitutively active (Palmiter, 2018), whereas in BRS3-CreER mice, tamoxifen administration provides temporal control of the recombinase activity (Piñol et al., 2018). Both drivers should express Cre with the same pattern as wild-type BRS3, and the BRS3-CreER mice express a Cre-dependent reporter with a pattern matching that of Brs3 mRNA (Piñol et al., 2018). The only previous information for BRS3-IRES-Cre mice is that the Cre-dependent reporter is expressed in the PBN (Palmiter, 2018). The GFP in BRS3-IRES-Cre mice was not detected, even using immunohistochemistry, presumably because of very low levels of expression of this receptor.

Here we report the tdTomato expression pattern in 5month-old BRS3-IRES-Cre;Ai14 mice in which tdTomato expression from the Ai14 gene is Cre dependent. These mice express the reporter in multiple hypothalamic regions [median POA (MnPO); medial POA (MPA); arcuate nucleus (Arc); LH; dorsal hypothalamic area] and other brain regions [striohypothalamic nucleus; bed nucleus of the stria terminalis (BNST); posterodorsal medial amygdala (MePD); PBN; and fibers in the substantia nigra reticular (SNR); Fig. 1B-D, Extended Data Fig. 1-1]. All of these regions overlap with the expression pattern in BRS3CreER;Ai14 mice. The BRS3-IRES-Cre also labeled additional cell bodies [indusium griseum (IG); caudate putamen or striatum (CPu); DG] and fibers [endopeduncular nucleus (EP)]. In summary, BRS3-IRES-Cre mice have reporter expression in all regions seen in BRS3-CreER mice, plus some additional sites.

\section{Lineage tracing in BRS3-IRES-Cre mice}

The additional reporter expression in BRS3-IRES-Cre mice could be from the following: (1) Cre expression in regions not normally expressing Brs3 (ectopic sites); (2) higher Cre expression in sites that do express Brs3 (eutopic sites); and/or (3) lineage effects with Cre expression in a precursor cell (or prior expression in the current cell). To distinguish among these possibilities, we injected a virus carrying a Cre-dependent GFP construct into three brain regions of BRS3-IRES-Cre;Ai14 and BRS3-CreER Ai14 mice. Cre activity is required at the time of virus injection/tamoxifen treatment for GFP expression while either prior or current Cre activity will produce a tdTomato signal (Fig. 2A).

In 3- to 5-month-old BRS3-CreER;Ai14 mice, virus-derived GFP was present in the DMH, but not the hippocampus or striatum (Fig. $2 B-D$ ). Virus-derived reporters have a higher copy number and are typically expressed at higher levels than host genome-derived reporters. Thus, lower eutopic Cre activity in BRS3-CreER;Ai14 mice likely does not explain the lack of GFP in the hippocampus and striatum.

BRS3-IRES-Cre;Ai14 mice showed the same viral GFP expression pattern (present in $\mathrm{DMH}$, but not in hippocampus or striatum) as the BRS3-CreER;Ai14 mice. Thus, at the time of viral injection, there was no active Cre recombinase in the hippocampus or striatum. As expected, the BRS3-IRES-Cre;Ai14 mice expressed tdTomato in all 

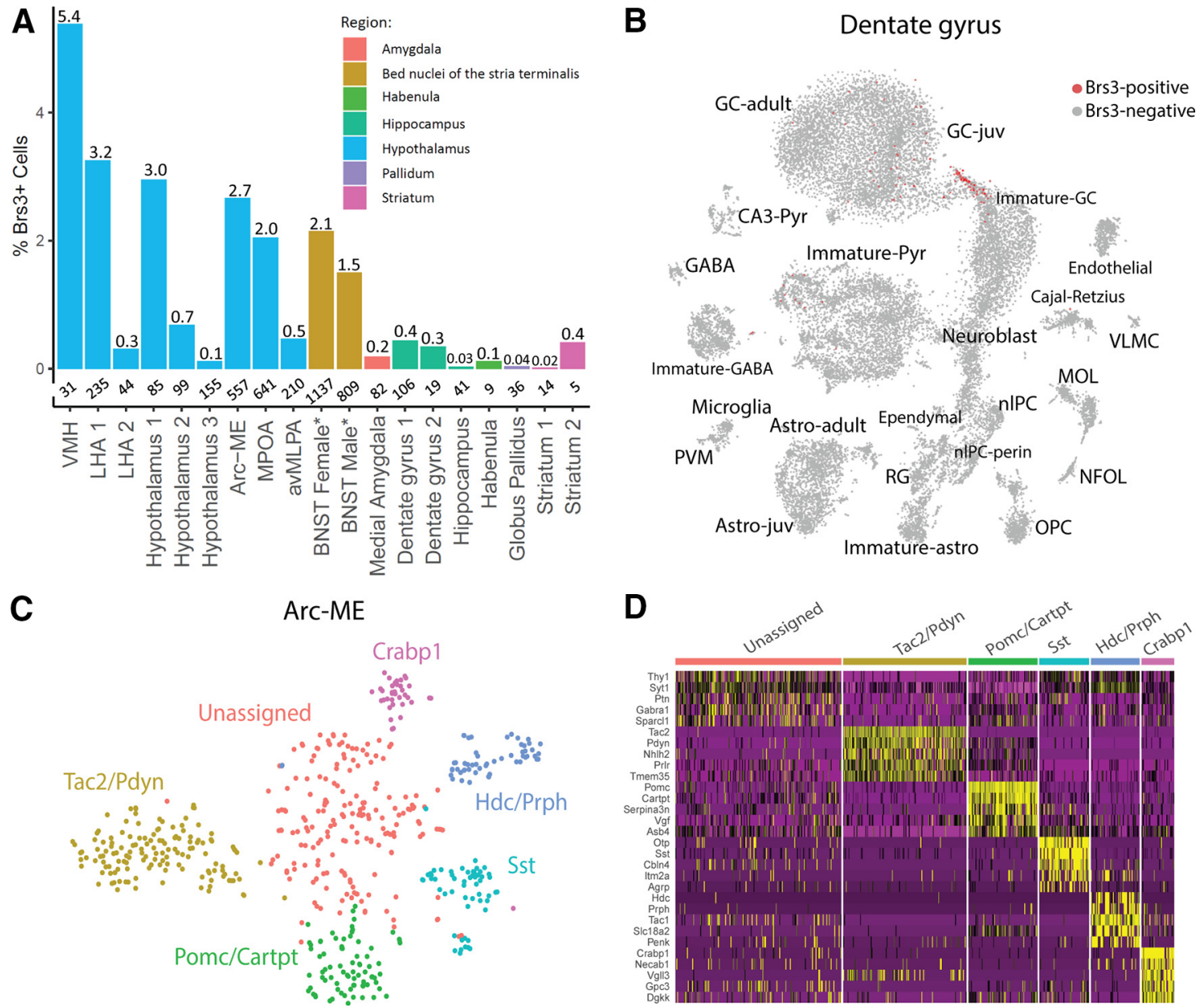

Figure 4. Brs3 expression in scRNA sequence datasets. A, Percentage of neurons expressing Brs3 in datasets with $\geq 5$ Brs3-positive cells (Extended Data Fig. 4-1, lists of datasets with fewer Brs3-positive cells). The number of detected Brs3-expressing cells is indicated below each bar. An *Total cells, not just neurons. Data are from the following, in order: GSE143818, GSE125065, GSE130597, GSE74672, GSE132355 GSE87544, GSE93374, GSE113576, GSE149344 GSE126836, GSE126836, GSE124061, GSE104323, GSE95315, GSE116470, GSE146983, GSE116470, GSE116470, and GSE82187. B, Dentate gyrus Brs3 expression from http://linnarssonlab.org/dentate/ (Hochgerner et al., 2018). C, t-SNE plot of the Brs3-expressing Arc-ME neurons. D, Heatmap of expression of the top five enriched genes in each cluster. The Brs3 clusters correspond to the original clusters as follows: Hdc/ Prph, n01 and n02; Tac2/Pdyn, n20; Pomc/Cartpt, n15 > n14; Crabp1, n26; and Sst, n23 > n12, and n13.

three regions. These results suggest that $\mathrm{Brs} 3$ is expressed earlier in hippocampal and striatal neuron development, but no longer at 3-5 months of age, consistent with lineage tracing in BRS3-IRES-Cre mice.

Examination of genomic reporter expression in BRS3IRES-Cre;Ai14 mice on P1 demonstrated expression in the striatum, $\mathrm{PVH}$, and PBN, but not the hippocampus (Fig. 3). By P23, all four of these regions contained tdTomato reporter. Together, the results suggest that striatal Brs 3 expression is on at (or before) P1 and turns off sometime before adulthood. Hippocampal Brs3 expression is initially off $(\mathrm{P} 1)$ and is turned on at (or before) P23.

\section{Brs3 expression as a defining feature of neuronal populations}

We next compared the Brs3 expression patterns determined from the Cre reporters with that in published mouse single-cell RNA datasets (Fig. 4A, Extended Data
Fig. 4-1) (Guo Q, Li JYH, 2019; Huang KW, Sabatini BL, 2020; Huang et al, 2019; Huisman et al., 2019; Mizrak et al., 2020; Tepe et al., 2018; Van Hove et al., 2019; Wizeman et al., 2019). Generally, the Brs3 scRNA expression/nonexpression pattern matched that in the BRS3Cre mice. For example, some striatal neurons were Brs3positive [5 of 368 or $1.4 \%$ (Gokce et al., 2016) and 14 of 72,897 or $0.019 \%$ (Saunders et al., 2018)]. In a hippocampus developmental series, Brs3 was expressed in immature and juvenile granule cell neurons of the dentate gyrus (Hochgerner et al., 2018; Fig. 4B).

No scRNA dataset had $>5 \%$ BRS3-positive cells. In scRNA datasets with >100 BRS3-positive cells (GSE93374, GSE104323, GSE113576, GSE125065, and GSE149344), the positivity was because of a single detected Brs3 transcript/cell in $69 \%, 86 \%, 68 \%, 63 \%$, and $81 \%$ of the cells, respectively, suggesting that Brs3 false-negative findings are likely. Assuming a Poisson distribution, the 
A AAV1-DIO-YFP AAV1-DIO-Synaptophysin-mCherry

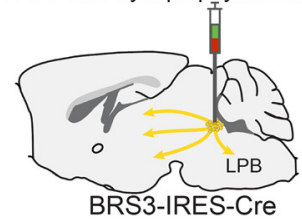

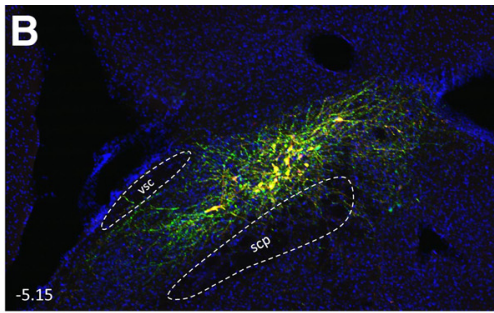

D
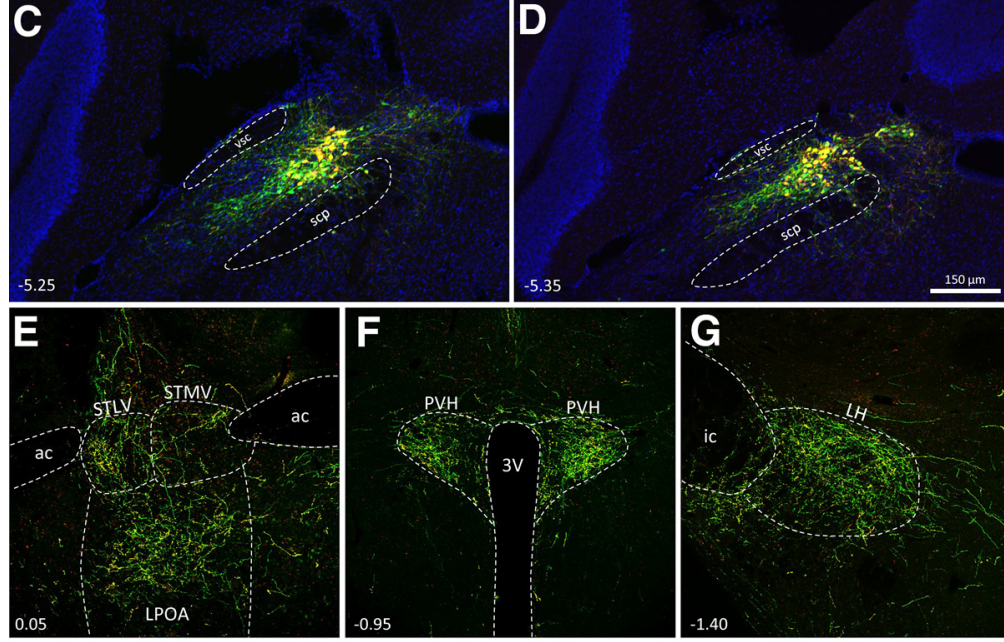

$\mathrm{H}$
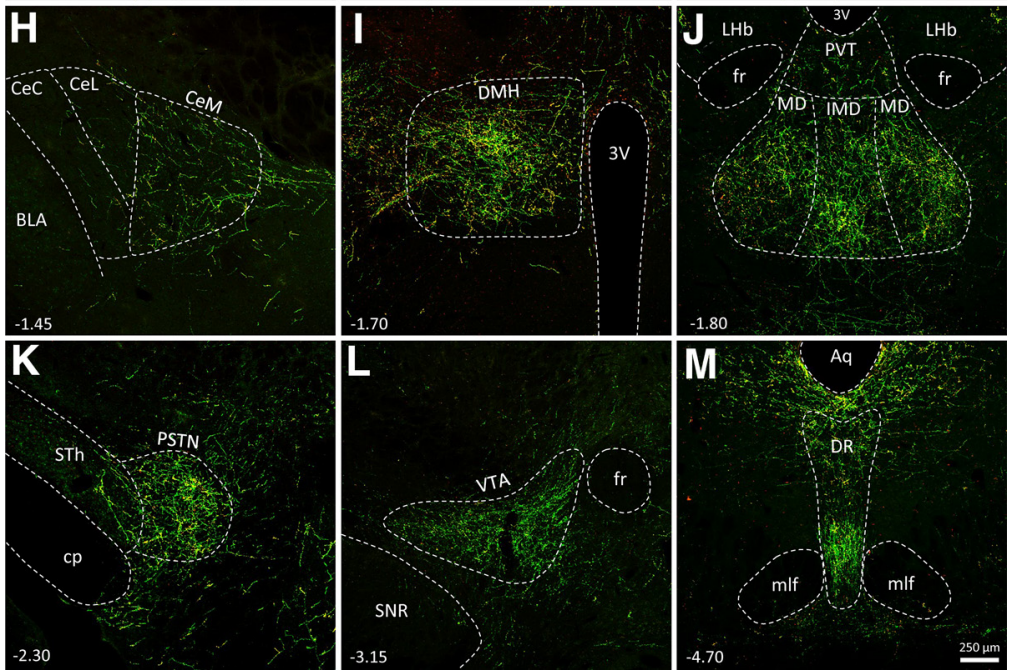

Figure 5. Brs3-expressing neurons in the lateral parabrachial nucleus project axons to multiple forebrain regions. AAV1-DIO-YFP and AAV1-DIO-synaptophysin:mCherry were coinjected into the PBN of BRS3-IRES-Cre mice. Several weeks later mice were perfused, sectioned, and then sections throughout the brain were treated with antibodies against YFP and DsRed to detect expression. Yellow reveals regions where both fluorescent proteins are present in cell bodies and terminals, whereas only green (e.g., VTA) reveals fibers of passage. $\boldsymbol{A}$, Diagram showing injection site. $\boldsymbol{B}-\boldsymbol{D}$, viral expression at three bregma levels of the PBN. $\boldsymbol{E}-\boldsymbol{M}$, Fluorescent fibers in preoptic area $(\boldsymbol{E})$; paraventricular nucleus $(\boldsymbol{F})$; lateral hypothalamus $(\boldsymbol{G})$; central nucleus of the amygdala $(\boldsymbol{H})$; dorsal medial hypothalamus $(\boldsymbol{I})$; intermediodorsal thalamus $(\boldsymbol{J})$; parasubthalamic nucleus $(\boldsymbol{K})$; ventral tegmental nucleus $(\boldsymbol{L})$; and dorsal raphe $(\boldsymbol{M})$. Bregma levels are indicated by numbers.

actual Brs3-positive percentages are 1.1-fold to 3-fold of the nominal percentages, depending on the dataset, normalization, and assumptions used in calculating event rates.

To explore the impact of the Brs3 false negative findings, we studied a dataset of Arc-ME scRNA sequences (Campbell et al., 2017), chosen for its large number of Brs3-positive neurons (4.2\% of total). Clustering only the
552 Brs3-positive neurons yielded six clusters, five of which mapped to nine of the clusters reported in the study by Campbell et al. (2017; Fig. 4C,D). Only two of the original clusters had high enough detected Brs3 positivity ( $46 \%$ in $\mathrm{n} 01$ and $42 \%$ in n02) to indicate that Brs3 might be present in all cluster members. Thus, removing the Brs3 detection bias did not improve the clustering analysis. 

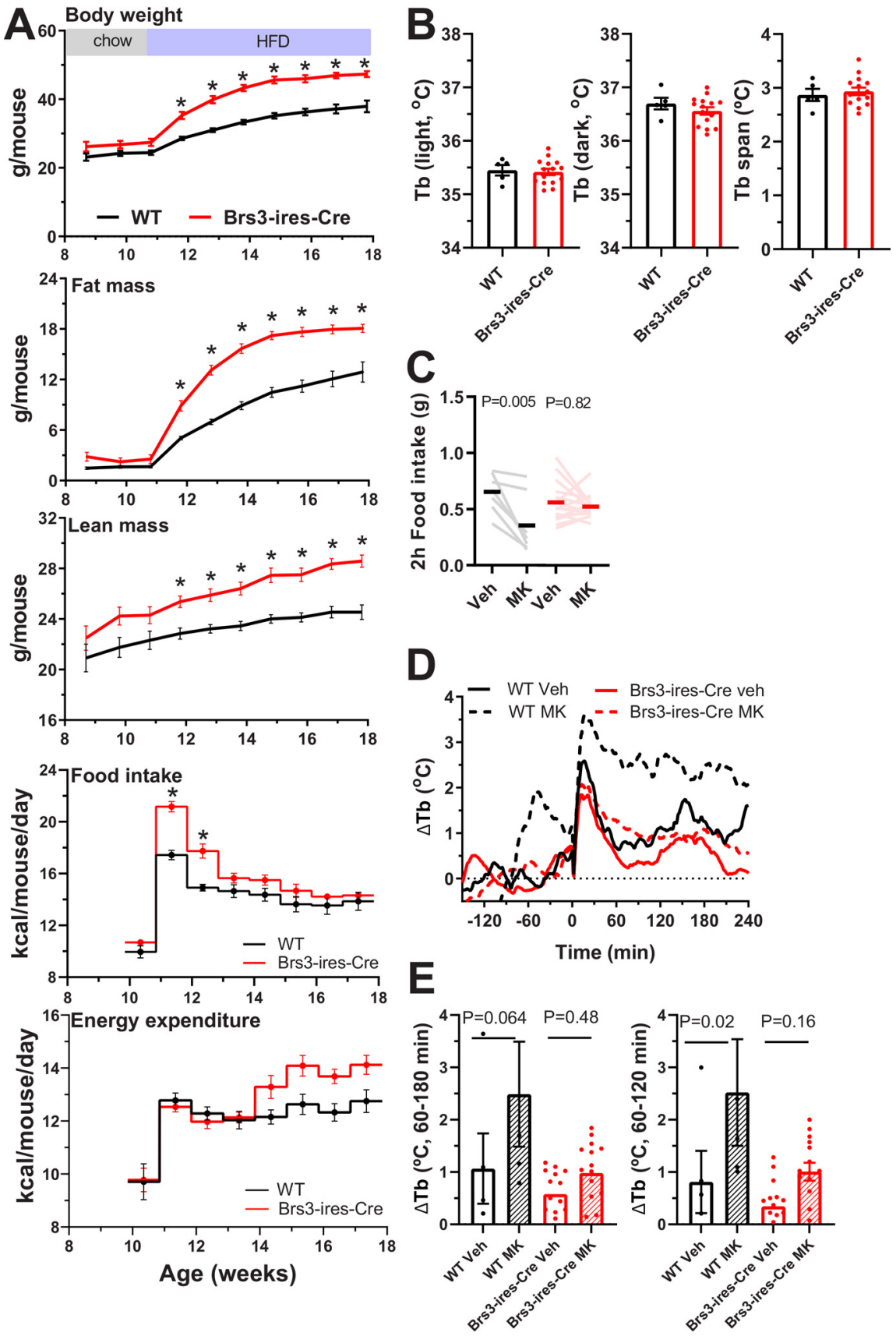

Figure 6. Metabolic phenotype of BRS3-IRES-Cre mice. A, Effect of a high-fat diet in male BRS3-IRES-Cre and littermate control mice ( $n=8$ /group) on body weight, fat mass, lean mass, food intake, and energy expenditure determined by mass balance (Ravussin et al., 2013). Data are the mean \pm SEM; *adjusted $p<0.05$ from two-way ANOVA (Extended Data Fig. 6-1, with Š́dák's multiple-comparisons test). $\boldsymbol{B}-\boldsymbol{D}$, Baseline core body temperature (B), effect of MK-5046 (10 mg/kg, i.p., given at onset of the dark cycle in $5 \mathrm{~h}$ fasted mice) on food intake (C), and effect of MK-5046 (10 mg/kg, i.p., at 10:00 A.M. in overnight-fasted mice) on body temperature $(\boldsymbol{D})$. $\boldsymbol{E}, \mathrm{Tb}$ changes from baseline $(-150$ to $-30 \mathrm{~min})$ to $60-180 \mathrm{~min}$ and $60-120 \mathrm{~min}$ after dosing in a crossover design. The $p$ values are from two-way ANOVA with Śídák's multiple-comparisons test, see Extended Data Figure 6-1. Mice in $\boldsymbol{B}-\boldsymbol{E}$ are chow-fed males ( $n=5-15 /$ group). In $\boldsymbol{D}$, data are the mean with the SEM omitted for visual clarity.

\section{Projections of $\mathrm{PBN}^{\mathrm{BRS} 3}$ neurons}

The PBN receives diverse sensory inputs and integrates and transmits this information to many forebrain regions (Palmiter, 2018; Chiang et al., 2019). As a step in characterizing PBN ${ }^{\mathrm{BRS} 3}$ neurons, the BRS3-IRES-Cre mouse was used to trace the projections from $\mathrm{PBN}^{\mathrm{BRS} 3}$ neurons
(Fig. 5). Projections were observed to the preoptic area (lateral POA), hypothalamus $(\mathrm{PVH}, \mathrm{LH}, \mathrm{DMH}$, principal sensory trigeminal nucleus), amygdala (BNST, central nucleus of the amygdala), thalamus [mediodorsal thalamus (MD), ipsilateral MD], and dorsal raphe; the VTA signal is likely caused by fibers of passage because synap- 


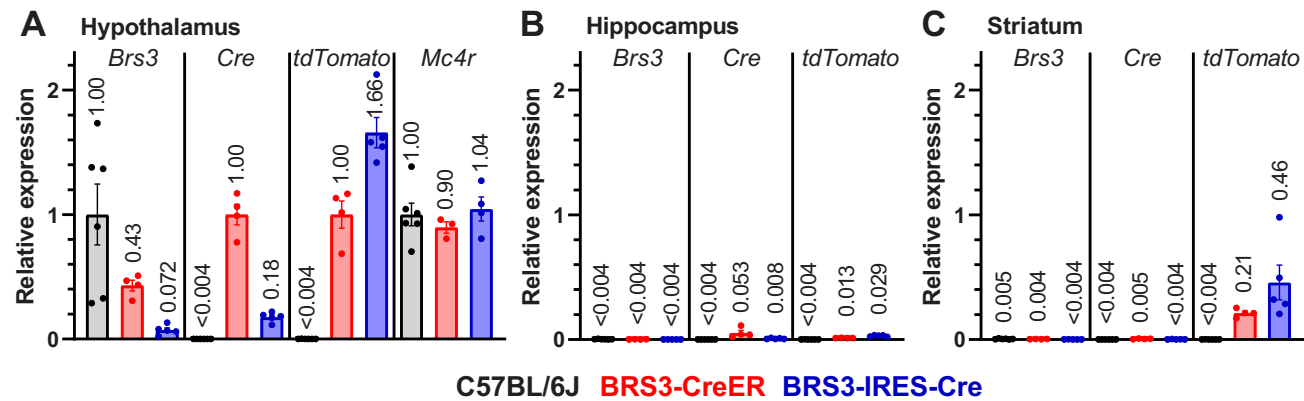

Figure 7. mRNA levels in hypothalamus, hippocampus, and striatum of the two BRS3-Cre mouse models. mRNA expression was quantified by RT-PCR in hypothalamus $(\boldsymbol{A})$, hippocampus $(\boldsymbol{B})$, and striatum $(\boldsymbol{C})$ of control (C57BL/6J, black), BRS3-CreER (red), and BRS3-IRES-Cre (blue) mice at 5-6 months of age. In all samples, Brs3 and Mc4r mRNA levels are normalized to the C57BL/6J hypothalamus, and Cre and tdTomato mRNA levels are normalized to the BRS3-CreER hypothalamus. Mc4r mRNA levels are a dissection and technical control. Mean values are indicated above each bar. Expression below the limit of detection is indicated as $<0.004$ ( $n=4-6$ /group).

tophysin expression in the region is very low. Most of these nuclei have a role in regulating energy homeostasis.

\section{Metabolic phenotype of BRS3-IRES-Cre mice}

The BRS3-CreER allele is hypomorphic (Piñol et al., 2018), so the effect of the BRS3-IRES-Cre allele on metabolic physiology was examined. Male BRS3IRES-Cre mice fed a chow diet were nonsignificantly heavier than control littermates by $1.8 \mathrm{~g}$ at 12 weeks (26.6 \pm 0.6 vs $24.8 \pm 0.7 \mathrm{~g}, p=0.087 ; n=9-15 /$ group) and by $1.5 \mathrm{~g}$ at 14 weeks (27.5 \pm 0.5 vs $26.1 \pm 4.4 \mathrm{~g}$, $p=0.10 ; n=7-15$ /group). In an independent cohort, male BRS3-IRES-Cre mice switched to a high-fat diet gained more weight and adiposity than littermate controls, initially with increased food intake and unchanged energy expenditure (Fig. 6A, Extended Data Fig. 6-1). The phenotype is similar to the BRS3-null mice (Ohki-Hamazaki et al., 1997b) and BRS3-CreER mice (Piñol et al., 2018).

A robust thermal phenotype of BRS3-null mice is an increased Tb span (defined as the difference between the 95th and 5th Tb percentiles over integral multiples of $24 \mathrm{~h}$ intervals; Xiao et al., 2017). The Tb span was not increased in the BRS3-IRES-Cre mice compared with wild-type littermates, and, as expected, there was no difference in either light- or dark-phase Tb (Fig. 6B).
However, the BRS3-IRES-Cre mice lost the suppression of food intake elicited by treatment with a BRS3 agonist, MK-5046 (Fig. 6C), and the BRS3 agonist effect of increasing light-phase Tb (Guan et al., 2011) was blunted in the BRS3-IRES-Cre mice (Fig. 6D,E). These results indicate that the BRS3-IRES-Cre allele is a hypomorph, with a phenotype milder than the complete BRS3-null mice.

\section{Reduced Brs3 mRNA levels in BRS3-IRES-Cre mice}

To better understand the phenotype of the BRS3-IRESCre mice, we measured RNA levels in 5- to 6-month-old, wild-type (C57BL/6J), BRS3-CreER;Ai14, and BRS3IRES-Cre;Ai14 (Fig. 7) mice. Hypothalamic Brs3 mRNA levels in BRS3-CreER mice were $43 \pm 4 \%$ of wild-type mice and $7.2 \pm 1.7 \%$ in BRS3-IRES-Cre mice. The relative RNA levels likely explain the more severe metabolic phenotype in the BRS3-IRES-Cre mice.

In both BRS3-Cre drivers, BRS3 and Cre are encoded in a single mRNA, and, as expected, the Brs3/Cre mRNA ratios were similar in the BRS3-CreER;Ai14 and BRS3IRES-Cre;Ai14 mice (2.3 and 3.4, respectively). Cre mRNA in the hypothalamus of BRS3-IRES-Cre mice is $18 \%$ of the level in BRS3-CreER mice. Interestingly, tdTomato mRNA levels in the hypothalamus of BRS3-IRES-Cre mice were $166 \%$ of that in BRS3-CreER mice, suggesting that there are more tdTomato-expressing neurons (and

Table 1: Summary of mouse Brs3 allele phenotypes

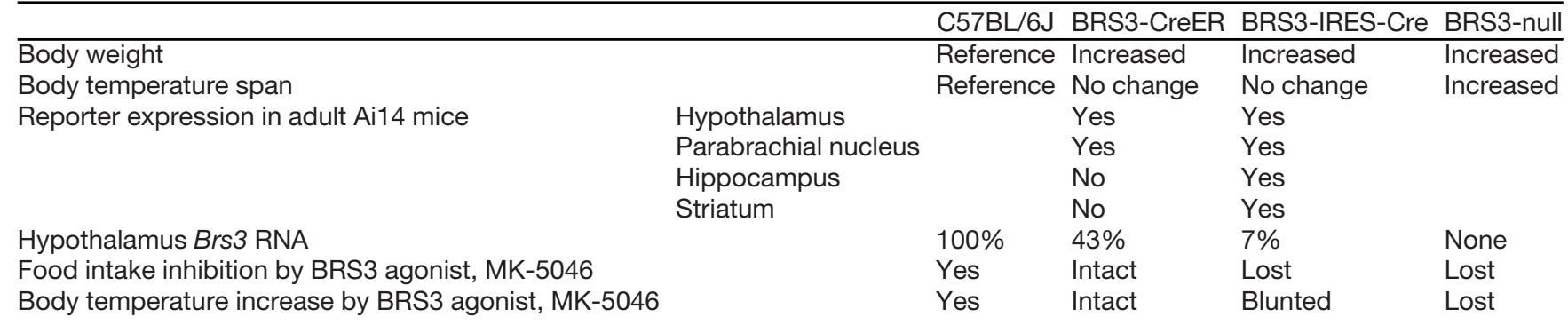

BRS3-IRES-Cre observations are presented in Results; BRS3-CreER data are from Results and the study by Piñol et al. (2018); and the BRS3-null phenotype is from the studies by Ohki-Hamazaki et al. (1997b), Guan et al. (2011), and Xiao et al. (2017), among others. 
not more tdTomato mRNA/cell since both mice use the same reporter locus) in BRS3-IRES-Cre;Ai14 mice. Possible mechanistic explanations for increased tdTomato-positive neurons are lineage effects in BRS3-IRES-Cre;Ai14 mice and/or incomplete activation of Cre by tamoxifen in BRS3CreER;Ai14 mice.

In the hippocampus, very low levels of Cre and tdTomato mRNA were detected in both BRS3-CreER; Ai14 and BRS3-IRES-Cre;Ai14 mice. In the striatum, low levels of tdTomato mRNA (BRS3-IRES-Cre > BRS3-CreER) were observed. Apparent differences between mRNA levels and fluorescence signal may be because of translational efficiency and/or protein stability, as protein levels were not quantitated.

\section{Discussion}

The design of genomic reporter/driver mice has evolved from random insertion of small-plasmid DNAs to random insertion of larger DNAs (e.g., bacterial artificial chromosomes), and to targeted insertion into the endogenous locus, recently with high efficiency using CRISPR/Cas9 technology. Thus, as with the BRS3-Cre mice, one can now reliably produce driver/reporter alleles that have a high likelihood of correctly tracking the expression pattern of the target gene, a major advance [see (Song and Palmiter, 2018; Luo et al., 2020) for some cautions].

Lineage effects in nonconditional systems are widely recognized (Daigle et al., 2018), but infrequently characterized in detail [exceptions are proopiomelanocortin (POMC; Padilla et al., 2010) and GFAP (Ganat et al., 2006)]. The differences between the two BRS3-Cre drivers illustrate the value of having available both inducible and constitutive recombinases.

The large doses of tamoxifen required for efficient Cre recombinase activity can reduce body weight and cause loss of adipose tissue (Ye et al., 2015). Also, Brs3 expression is sex dimorphic (Xu et al., 2012; Chen et al., 2019), and $B r s 3$ neurons are involved in sex-dimorphic behaviors that may be regulated by estrogen receptors (Moffitt et al., 2018). Thus, the ability to select inducible, tamoxifendependent, and/or constitutive tamoxifen-independent driver mice improves experimental design.

The Brs3 locus is unforgiving for expressing a recombinase/reporter allele since Brs3 is on the $\mathrm{X}$ chromosome, undergoes $\mathrm{X}$-inactivation, and is expressed at a low level. Thus, modified alleles must preserve BRS3 function while optimizing reporter expression. Unfortunately, both BRS3Cre alleles are hypomorphs, with more function in BRS3CreER than BRS3-IRES-Cre allele (Table 1, summary), and the metabolic effects of the deficiency should be considered when the mice are used.

Each allele produces a single mRNA that encodes both BRS3 and Cre. The T2A sequence in BRS3-CreER causes a ribosome skip, with the downstream protein being produced in similar amounts to the upstream one, although the upstream protein has 17 aa appended, which may affect function (Szymczak-Workman et al., 2012). In the BRS3-IRES-Cre allele, the IRES system results in translation of the downstream Cre at a fraction of the level of the upstream gene (Mizuguchi et al., 2000). While the T2A and IRES sequences differentially affect protein levels, they do not explain the reduced Brs3 mRNA levels, which are presumably because of mRNA instability or reduced transcription caused by the inserted genomic sequences, such as by interfering with enhancer function. It is notable that the BRS3-IRES-Cre allele produces efficient recombination despite a $93 \%$ reduction in Brs3 mRNA levels and further reduced Cre protein because of the IRES. The effectiveness of the recombinase means that quantitative differences in Brs3 mRNA levels, such as the sex dimorphism in the BNST and medial amygdala (Xu et al., 2012; Chen et al., 2019), are not detected in reporter mice.

The availability of characterized BRS3-Cre driver alleles facilitates investigation of BRS3 function in pancreatic islets (Feng et al., 2011), neuroendocrine tumors (Sherman et al., 2014), and certain cancers (Moreno et al., 2018; Ramos-Alvarez et al., 2019). The limited number of discrete brain nuclei expressing Brs3 means that the BRSCre drivers are particularly valuable for intersectional genetic studies (Madisen et al., 2015) of the neural circuits and networks that control metabolism and other processes.

\section{References}

Butler A, Hoffman P, Smibert P, Papalexi E, Satija R (2018) Integrating single-cell transcriptomic data across different conditions, technologies, and species. Nat Biotechnol 36:411-420.

Campbell JN, Macosko EZ, Fenselau H, Pers TH, Lyubetskaya A, Tenen D, Goldman M, Verstegen AM, Resch JM, McCarroll SA, Rosen ED, Lowell BB, Tsai LT (2017) A molecular census of arcuate hypothalamus and median eminence cell types. Nat Neurosci 20:484-496.

Chen PB, Hu RK, Wu YE, Pan L, Huang S, Micevych PE, Hong W (2019) Sexually dimorphic control of parenting behavior by the medial amygdala. Cell 176:1206-1221.e18.

Chiang MC, Bowen A, Schier LA, Tupone D, Uddin O, Heinricher MM (2019) Parabrachial complex: a hub for pain and aversion. J Neurosci 39:8225-8230.

Daigle TL, Madisen L, Hage TA, Valley MT, Knoblich U, Larsen RS, Takeno MM, Huang L, Gu H, Larsen R, Mills M, Bosma-Moody A, Siverts LA, Walker M, Graybuck LT, Yao Z, Fong O, Nguyen TN, Garren E, Lenz GH, et al (2018) A suite of transgenic driver and reporter mouse lines with enhanced brain-cell-type targeting and functionality. Cell 174:465-480.e22.

Feng Y, Guan XM, Li J, Metzger JM, Zhu Y, Juhl K, Zhang BB, Thornberry NA, Reitman ML, Zhou YP (2011) Bombesin receptor subtype-3 (BRS-3) regulates glucose-stimulated insulin secretion in pancreatic islets across multiple species. Endocrinology 152:4106-4115.

Franklin KBJ, Paxinos G (2007) The mouse brain in stereotaxic coordinates, Ed 3. New York: Academic.

Ganat YM, Silbereis J, Cave C, Ngu H, Anderson GM, Ohkubo Y, Ment LR, Vaccarino FM (2006) Early postnatal astroglial cells produce multilineage precursors and neural stem cells in vivo. J Neurosci 26:8609-8621.

Gokce O, Stanley GM, Treutlein B, Neff NF, Camp JG, Malenka RC, Rothwell PE, Fuccillo MV, Südhof TC, Quake SR (2016) Cellular taxonomy of the mouse striatum as revealed by single-cell RNAseq. Cell Rep 16:1126-1137.

González N, Moreno P, Jensen RT (2015) Bombesin receptor subtype 3 as a potential target for obesity and diabetes. Expert Opin Ther Targets 19:1153-1170.

Guan X-M, Chen H, Dobbelaar PH, Dong Y, Fong TM, Gagen K, Gorski J, He S, Howard AD, Jian T, Jiang M, Kan Y, Kelly TM, 
Kosinski J, Lin LS, Liu J, Marsh DJ, Metzger JM, Miller R, Nargund RP, et al. (2010) Regulation of energy homeostasis by bombesin receptor subtype-3: selective receptor agonists for the treatment of obesity. Cell Metab 11:101-112.

Guan X-M, Metzger JM, Yang L, Raustad KA, Wang S-P, Spann SK, Kosinski JA, Yu H, Shearman LP, Faidley TD, Palyha O, Kan Y, Kelly TM, Sebhat I, Lin LS, Dragovic J, Lyons KA, Craw S, Nargund RP, Marsh DJ, et al. (2011) Antiobesity effect of MK-5046, a novel bombesin receptor subtype-3 agonist. J Pharmacol Exp Ther 336:356-364.

Guo Q, Li JYH (2019) Defining developmental diversification of diencephalon neurons through single cell gene expression profiling. Development 146:dev174284.

Hirooka A, Hamada M, Fujiyama D, Takanami K, Kobayashi Y, Oti T, Katayama Y, Sakamoto T, Sakamoto H (2021) The gastrin-releasing peptide/bombesin system revisited by a reverse-evolutionary study considering Xenopus. Sci Rep 11:13315.

Hochgerner H, Zeisel A, Lönnerberg P, Linnarsson S (2018) Conserved properties of dentate gyrus neurogenesis across postnatal development revealed by single-cell RNA sequencing. Nat Neurosci 21:290-299.

Huang KW, Sabatini BL (2020) Single-cell analysis of neuroinflammatory responses following intracranial injection of $\mathrm{G}$-deleted rabies viruses. Front Cell Neurosci 14:65.

Huang KW, Ochandarena NE, Philson AC, Hyun M, Birnbaum JE, Cicconet M, Sabatini BL (2019) Molecular and anatomical organization of the dorsal raphe nucleus. Elife 8:e46464.

Huisman C, Cho H, Brock O, Lim SJ, Youn SM, Park Y, Kim S, Lee SK, Delogu A, Lee JW (2019) Single cell transcriptome analysis of developing arcuate nucleus neurons uncovers their key developmental regulators. Nat Commun 10:3696.

Jensen RT, Battey JF, Spindel ER, Benya RV (2008) International Union of Pharmacology. LXVIII. Mammalian bombesin receptors: nomenclature, distribution, pharmacology, signaling, and functions in normal and disease states. Pharmacol Rev 60:1-42.

Kiyotsuka Y, Shimada K, Kobayashi S, Suzuki M, Akiu M, Asano M, Sogawa $Y$, Hara T, Konishi M, Abe-Ohya R, Izumi M, Nagai $Y$, Yoshida K, Abe Y, Takamori H, Takahashi H (2016) Synthesis and biological evaluation of novel imidazol-1-ylacetic acid derivatives as non-brain penetrant bombesin receptor subtype-3 (BRS-3) agonists. Bioorg Med Chem Lett 26:4205-4210.

Lateef DM, Xiao C, Brychta RJ, Diedrich A, Schnermann J, Reitman ML (2016) Bombesin-like receptor 3 regulates blood pressure and heart rate via a central sympathetic mechanism. Am J Physiol Heart Circ Physiol 310:H891-898.

Liu J, Lao ZJ, Zhang J, Schaeffer MT, Jiang MM, Guan XM, Van der Ploeg LH, Fong TM (2002) Molecular basis of the pharmacological difference between rat and human bombesin receptor subtype- 3 (BRS-3). Biochemistry 41:8954-8960.

Luo L, Ambrozkiewicz MC, Benseler F, Chen C, Dumontier E, Falkner S, Furlanis E, Gomez AM, Hoshina N, Huang $W-H$, Hutchison MA, Itoh-Maruoka Y, Lavery LA, Li W, Maruo T, Motohashi J, Pai EL-L, Pelkey KA, Pereira A, Philips T, et al. (2020) Optimizing nervous system-specific gene targeting with Cre driver lines: prevalence of germline recombination and influencing factors. Neuron 106:37-65.e5.

Madisen L, Zwingman TA, Sunkin SM, Oh SW, Zariwala HA, Gu H, $\mathrm{Ng}$ LL, Palmiter RD, Hawrylycz MJ, Jones AR, Lein ES, Zeng H (2010) A robust and high-throughput Cre reporting and characterization system for the whole mouse brain. Nat Neurosci 13:133140.

Madisen L, Garner AR, Shimaoka D, Chuong AS, Klapoetke NC, Li L, van der Bourg A, Niino Y, Egolf L, Monetti C, Gu H, Mills M, Cheng A, Tasic B, Nguyen TN, Sunkin SM, Benucci A, Nagy A, Miyawaki A, Helmchen F, et al. (2015) Transgenic mice for intersectional targeting of neural sensors and effectors with high specificity and performance. Neuron 85:942-958.

Mantey SA, Weber HC, Sainz E, Akeson M, Ryan RR, Pradhan TK, Searles RP, Spindel ER, Battey JF, Coy DH, Jensen RT (1997) Discovery of a high affinity radioligand for the human orphan receptor, bombesin receptor subtype 3 , which demonstrates that it has a unique pharmacology compared with other mammalian bombesin receptors. J Biol Chem 272:26062-26071.

Maruyama M, Hotta N, Nio Y, Hamagami K, Nagi T, Funata M, Sakamoto J, Nakakariya M, Amano N, Nishida M, Okawa T, Arikawa Y, Sasaki S, Kasai S, Nagisa Y, Habata Y, Mori M (2018) Bombesin receptor subtype-3-expressing neurons regulate energy homeostasis through a novel neuronal pathway in the hypothalamus. Brain Behav 8:e00881.

Mizrak D, Bayin NS, Yuan J, Liu Z, Suciu RM, Niphakis MJ, Ngo N, Lum KM, Cravatt BF, Joyner AL, Sims PA (2020) Single-cell profiling and SCOPE-seq reveal lineage dynamics of adult ventricularsubventricular zone neurogenesis and NOTUM as a key regulator. Cell Rep 31:107805.

Mizuguchi H, Xu Z, Ishii-Watabe A, Uchida E, Hayakawa T (2000) IRES-dependent second gene expression is significantly lower than cap-dependent first gene expression in a bicistronic vector. Mol Ther 1:376-382.

Moffitt JR, Bambah-Mukku D, Eichhorn SW, Vaughn E, Shekhar K, Perez JD, Rubinstein ND, Hao J, Regev A, Dulac C, Zhuang X (2018) Molecular, spatial, and functional single-cell profiling of the hypothalamic preoptic region. Science 362:eaau5324.

Moreno P, Mantey SA, Lee SH, Ramos-Álvarez I, Moody TW, Jensen RT (2018) A possible new target in lung-cancer cells: the orphan receptor, bombesin receptor subtype-3. Peptides 101:213-226.

Nio Y, Hotta N, Maruyama M, Hamagami K, Nagi T, Funata M, Sakamoto J, Nakakariya M, Amano N, Okawa T, Arikawa Y, Sasaki S, Okuda S, Kasai S, Habata Y, Nagisa Y (2017) A Selective bombesin receptor subtype 3 agonist promotes weight loss in male dietinduced-obese rats with circadian rhythm change. Endocrinology 158:1298-1313.

Oh SW, Harris JA, Ng L, Winslow B, Cain N, Mihalas S, Wang Q, Lau C, Kuan L, Henry AM, Mortrud MT, Ouellette B, Nguyen TN, Sorensen SA, Slaughterbeck CR, Wakeman W, Li Y, Feng D, Ho A, Nicholas E, et al. (2014) A mesoscale connectome of the mouse brain. Nature 508:207-214.

Ohki-Hamazaki H, Wada E, Matsui K, Wada K (1997a) Cloning and expression of the neuromedin $B$ receptor and the third subtype of bombesin receptor genes in the mouse. Brain Res 762:165-172.

Ohki-Hamazaki H, Watase K, Yamamoto K, Ogura H, Yamano M, Yamada K, Maeno H, Imaki J, Kikuyama S, Wada E, Wada K (1997b) Mice lacking bombesin receptor subtype-3 develop metabolic defects and obesity. Nature 390:165-169.

Padilla SL, Carmody JS, Zeltser LM (2010) Pomc-expressing progenitors give rise to antagonistic neuronal populations in hypothalamic feeding circuits. Nat Med 16:403-405.

Palmiter RD (2018) The parabrachial nucleus: CGRP neurons function as a general alarm. Trends Neurosci 41:280-293.

Piñol RA, Zahler SH, Li C, Saha A, Tan BK, Škop V, Gavrilova O, Xiao C, Krashes MJ, Reitman ML (2018) Brs3 neurons in the mouse dorsomedial hypothalamus regulate body temperature, energy expenditure, and heart rate, but not food intake. Nat Neurosci 21:1530-1540.

Piñol RA, Mogul AS, Hadley CK, Saha A, Li C, Škop, V, Province HS, Xiao C, Gavrilova O, Krashes MJ, Reitman ML (2021) Preoptic BRS3 neurons increase body temperature and heart rate via multiple pathways. Cell Metab 33:1389-1403.e6.

Ramos-Alvarez I, Lee L, Mantey SA, Jensen RT (2019) Development and characterization of a novel, high-affinity, specific, radiolabeled ligand for BRS-3 receptors. J Pharmacol Exp Ther 369:454-465.

Ravussin Y, Gutman R, LeDuc CA, Leibel RL (2013) Estimating energy expenditure in mice using an energy balance technique. Int $\mathrm{J}$ Obes (Lond) 37:399-403.

Reitman ML, Dishy V, Moreau A, Denney WS, Liu C, Kraft WK, Mejia AV, Matson MA, Stoch SA, Wagner JA, Lai E (2012) Pharmacokinetics and pharmacodynamics of MK-5046, a bombesin receptor subtype-3 (BRS-3) agonist, in healthy patients. J Clin Pharmacol 52:1306-1316.

Sano H, Feighner SD, Hreniuk DL, Iwaasa H, Sailer AW, Pan J, Reitman ML, Kanatani A, Howard AD, Tan CP (2004) Characterization of the 
bombesin-like peptide receptor family in primates. Genomics 84:139-146.

Saunders A, Macosko EZ, Wysoker A, Goldman M, Krienen FM, de Rivera H, Bien E, Baum M, Bortolin L, Wang S, Goeva A, Nemesh J, Kamitaki N, Brumbaugh S, Kulp D, McCarroll SA (2018) Molecular diversity and specializations among the cells of the adult mouse brain. Cell 174:1015-1030.e16.

Sherman SK, Maxwell JE, Carr JC, Wang D, Bellizzi AM, Sue O'Dorisio M, O'Dorisio TM, Howe JR (2014) Gene expression accurately distinguishes liver metastases of small bowel and pancreas neuroendocrine tumors. Clin Exp Metastasis 31:935-944.

Song AJ, Palmiter RD (2018) Detecting and avoiding problems when using the cre-lox system. Trends Genet 34:333-340.

Stuart T, Butler A, Hoffman P, Hafemeister C, Papalexi E, Mauck WM 3rd, Hao Y, Stoeckius M, Smibert P, Satija R (2019) Comprehensive integration of single-cell data. Cell 177:18881902.e21.

Szymczak-Workman AL, Vignali KM, Vignali DA (2012) Design and construction of $2 \mathrm{~A}$ peptide-linked multicistronic vectors. Cold Spring Harb Protoc 2012:199-204.

Tepe B, Hill MC, Pekarek BT, Hunt PJ, Martin TJ, Martin JF, Arenkiel BR (2018) Single-cell RNA-seq of mouse olfactory bulb reveals cellular heterogeneity and activity-dependent molecular census of adult-born neurons. Cell Rep 25:2689-2703.e3.

Van Hove H, Martens L, Scheyltjens I, De Vlaminck K, Pombo Antunes AR, De Prijck S, Vandamme N, De Schepper S, Van Isterdael G, Scott CL, Aerts J, Berx G, Boeckxstaens GE, Vandenbroucke RE, Vereecke L, Moechars D, Guilliams M, Van Ginderachter JA, Saeys Y, Movahedi K (2019) A single-cell atlas of mouse brain macrophages reveals unique transcriptional identities shaped by ontogeny and tissue environment. Nat Neurosci 22:1021-1035.

Wizeman JW, Guo Q, Wilion EM, Li JY (2019) Specification of diverse cell types during early neurogenesis of the mouse cerebellum. Elife 8:e42388.

Xiao C, Reitman ML (2016) Bombesin-like receptor 3: physiology of a functional orphan. Trends Endocrinol Metab 27:603-605.
Xiao C, Goldgof M, Gavrilova O, Reitman ML (2015) Anti-obesity and metabolic efficacy of the $\beta 3$-adrenergic agonist, CL316243, in mice at thermoneutrality compared to $22^{\circ} \mathrm{C}$. Obesity (Silver Spring) 23:1450-1459.

Xiao C, Piñol RA, Carlin JL, Li C, Deng C, Gavrilova O, Reitman ML (2017) Bombesin-like receptor 3 (Brs3) expression in glutamatergic, but not GABAergic, neurons is required for regulation of energy metabolism. Mol Metab 6:1540-1550.

Xiao C, Liu N, Province H, Piñol RA, Gavrilova O, Reitman ML (2020) BRS3 in both MC4R- and SIM1-expressing neurons regulates energy homeostasis in mice. Mol Metab 36:100969.

Xu X, Coats JK, Yang CF, Wang A, Ahmed OM, Alvarado M, Izumi T, Shah NM (2012) Modular genetic control of sexually dimorphic behaviors. Cell 148:596-607.

Yamada K, Wada E, Imaki J, Ohki-Hamazaki H, Wada K (1999) Hyperresponsiveness to palatable and aversive taste stimuli in genetically obese (bombesin receptor subtype-3-deficient) mice. Physiol Behav 66:863-867.

Yamada K, Ohki-Hamazaki H, Wada K (2000) Differential effects of social isolation upon body weight, food consumption, and responsiveness to novel and social environment in bombesin receptor subtype-3 (BRS-3) deficient mice. Physiol Behav 68:555-561.

Ye R, Wang QA, Tao C, Vishvanath L, Shao M, McDonald JG, Gupta RK, Scherer PE (2015) Impact of tamoxifen on adipocyte lineage tracing: inducer of adipogenesis and prolonged nuclear translocation of Cre recombinase. Mol Metab 4:771-778.

Yoshihara C, Tokita K, Maruyama T, Kaneko M, Tsuneoka Y, Fukumitsu K, Miyazawa E, Shinozuka K, Huang AJ, Nishimori K, McHugh TJ, Tanaka M, Itohara S, Touhara K, Miyamichi K, Kuroda KO (2021) Calcitonin receptor signaling in the medial preoptic area enables risk-taking maternal care. Cell Rep 35:109204.

Zhang L, Parks GS, Wang Z, Wang L, Lew M, Civelli O (2013) Anatomical characterization of bombesin receptor subtype-3 mRNA expression in the rodent central nervous system. J Comp Neurol 521:1020-1039. 